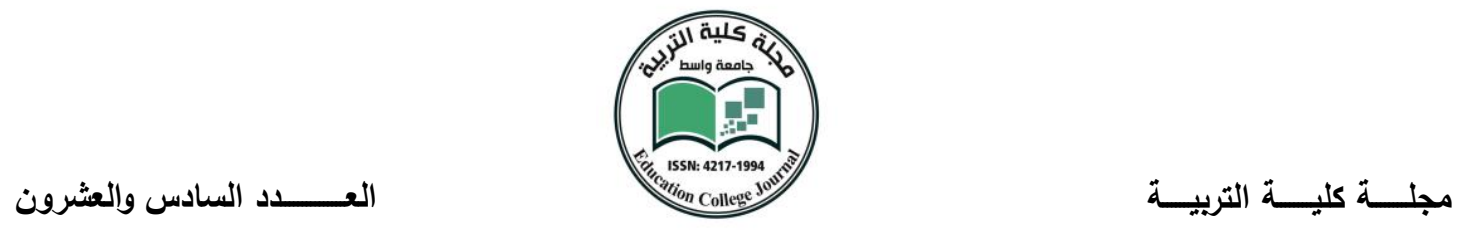

\title{
Study of Histopathological changes associated with FelinePan Leukopenia Virus infection in naturally infected cats
}

\author{
Hussein A. M. Al.Bayati
}

Vet. Med College . Wasit University

\author{
Sattar R.S. Al.Akaby \\ Vet. Med College . Wasit University
}

\section{Abstract}

Feline Pan Leukopenia Virus (FPV) was the more serious enteric viral infection of cats at different periods of life. Also had different generalized effects on many vital organs. The current study, aimed to investigate the essential pathological lesions which caused by the virus infection. The study which carried out on 37 infected cats at age range from $3-36$ months, these cats were checked previously at rapid test and PCR techniques .

The autopsy samples were removed from infected animals and study the histopathological changes, including bowel, heart, spleen, tongue, kidney and lung, 10 pieces of each.The results had a significant effect on the animal's life . The histopathological findings were appeared at the level of severe acute infection ,thus lastly caused death. Furthermore, the results revealed that the virus can cause different inflammatory changes at different vital organs .

Key Words . Feline parvovirus, Enteritis, histopathology .

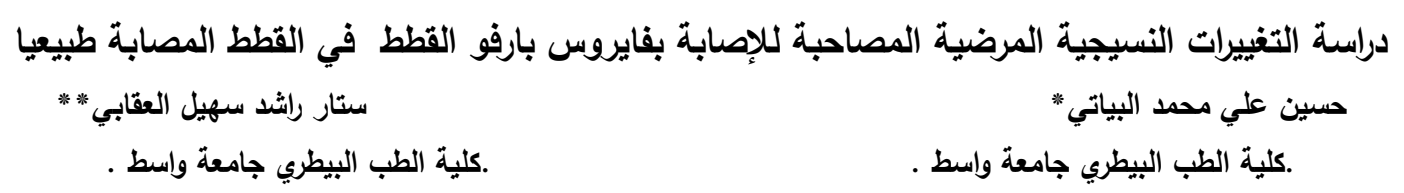

\section{الخلاصة}

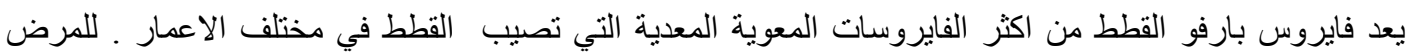

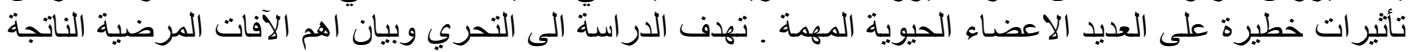

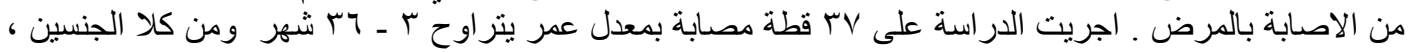

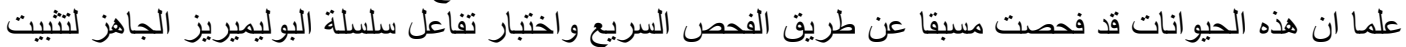

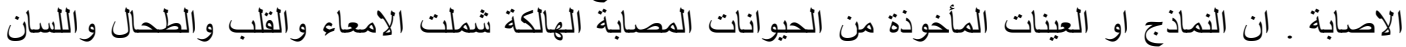

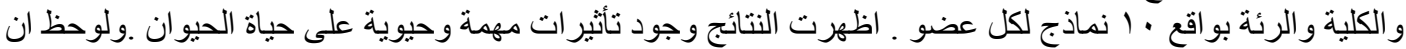

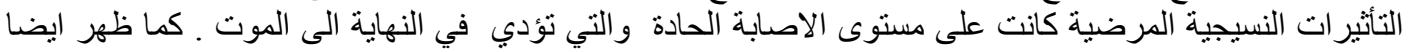

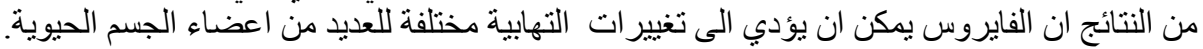

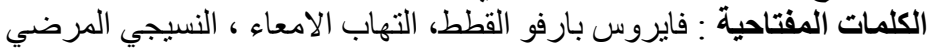




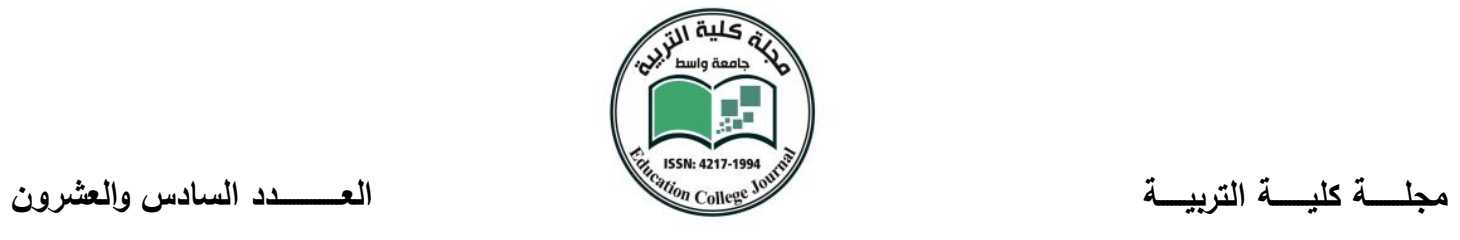

Introduction

Feline panleukopenia virus (FPV) was a serious contagious viral disease of kittens and adult cats, responsible for high mortality(1). FPV was the singlestranded DNA-including this virus, it was a highly serious disease infecting all individuals of Felidae (2). Besides FPV, new antigenic variants of the original $\mathrm{CPV}$, were also able to grow and infect cats (3).The importance of clinical signs depends on age, immune competence, and Co infections( 4 ). Clinical disease ranges from subclinical infection to a peracute syndrome with a sudden onset of decrease body temperature then followed by death(5).

FPV leads to generalized systemic infection, its requirements were rapidly dividing cells to produce infection, and the distribution of damages occurs in tissues with a greatest rate of mitotic activity at $\mathrm{S}$ phase of cell cycle (1). "Intestinal mucosal crypts (intestinal glands) Lymphoid tissue, bone marrow, were the most commonly invaded in adult animals".

Late period of pregnancy and early age period, the infection which result in some lymphoid and bone marrow defects, besides" the defects at central neural system (CNS), including the cerebrum, the cerebellum, the retina, and optic nerves, can be included " $(1,6,7)$. The present study was aimed to investigate and study the pathological aspects of the virus on different vital body organs .

\section{Materials and Methods}

\section{Collection and preparation of samples}

The autopsy samples were removed from stray and pet cats which were naturally infected with the virus and then study of histopathological changes caused by the disease. The organs were studied bowel, heart, spleen, tongue, kidney and lung, 10 pieces of each. Of note, the age range occure between 3 - 36 months and its weight between $0.3 \mathrm{~kg}$ and $2 \mathrm{~kg}$ at both sexes, these samples were taken from dead cats or by euthanasia(mercy killing) .

These cases were checked previously (other study) had positive infection by rapid test and ready PCR (8). Histopathological study was done by taken small pieces may be $\left(1 \mathrm{~cm}^{3}\right)$ from autopsy samples include intestine, heart, spleen, lung which were fixed at $10 \%$ buffered formalin, then embedded in paraffin, cut at 


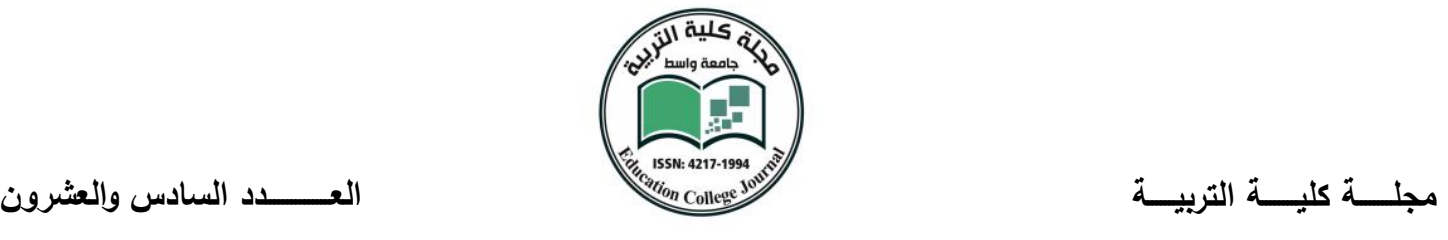

$5 \mu \mathrm{m}$, then stained with hematoxylin and eosin and then examined by light microscope according to Luna and Lee $(9)$.

\section{Results}

Pathological findings: Variable pathological finding were present in cats which naturally infected with feline panleukopenia virus (FPV):- In case of intestine the main histopathological lesion are seen in mucosal layer of intestine and characterized by the villi are shorted and atrophied and the cyrpts of intestinal mucosa are dilated and shriveled due to desquamation of epithelial cells and necrosis of crypts cells, in certain section sever hemorrhagic areas in the mucosal layer of intestine and mild inflammatory cells infiltrations mainly macrophages and few neutrophils and lymphocytes (Fig.1A). The microscopic lesion of the heart which appeared as myocarditis which characterized by mixed inflammatory cells infiltrations mainly neutrophils, lymphocytes ,macrophages and plasma cells in cardiac muscles fibers, and in some section of heart appeared as acute cellular swelling in myocardial muscles fibers in addition to edema infiltrated between muscle fibers and increased acidophilia of muscle sarcoplasm . (Fig.1B, Fig.2A).

The histopathological lesion of tongue there is severe hydropic degeneration in epithelium of mucosal tongue which characterized by the cells are swelling, and vacuolated appearance, in other areas of tissue there was severe inflammatory cells infiltrations mainly macrophages, plasma cells, lymphocytes and neutrophils in the lamina properia of mucosal tongue and surroundings areas also there is congestion of blood vessels (Fig 2B, Fig 3A). Lung and pleura were showed there is interstitial pneumonia which characterized by thickening of alveolar wall due to severe mononuclear cells infiltrations (MNCs) mainly lymphocytes, macrophages and few neutrophils and congestions of alveolar capillaries and proliferation of type 2 pneumocytes with peribronchial lymphoid tissue hyperplasia, in certain section extensive emphysematous area are seen in pulmonary tissue, in addition to extensive pulmonary edema and sever hemorrhage (Fig 3B, Fig4A,B).

While in the pleura the main lesion in this organ was fibrinous pleuritis which showed severe chronic and acute inflammatory cells exudations mainly neutrophils , lymphocytes, plasma cells and fibrinous exudates in pleural tissue(Fig.5A). In Kidneys microscopically, there were tubular necrosis and mild degenerative changes such as cloudy swelling were seen in proximal and distal convoluted 


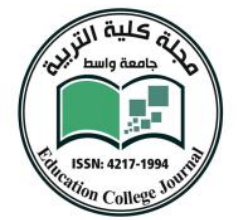

tubules with dilation of Bowman's space also there was mild infiltrations of MNCs such as lymphocytes and plasma cells between renal tubules, in certain section there was presences of eosinophilic intra nuclear inclusion bodies of the virus in epithelium of renal tubules with congestion of blood vessels (Fig6A).

The Spleen lesions were showed hyperplasia of white pulp in which extensive proliferation of the lymphocytes and macrophages in the periarterial sheath region (T-cells region ) and in remainder areas of white pulp (B-cells region), with extensive hyperplasia of smooth muscles of trabecule. Also reticulo-endothelial cells hyperplasia observed in red pulp in addition there was congestion of blood vessels ( Fig 6 B) while in other tissue there was hypocellulirty of white pulp due to sever lymphoid depletions and lack of lymphocytes and macrophages proliferations around central artery in white pulp and other area of red pulp of spleen (Fig 7A,B) .
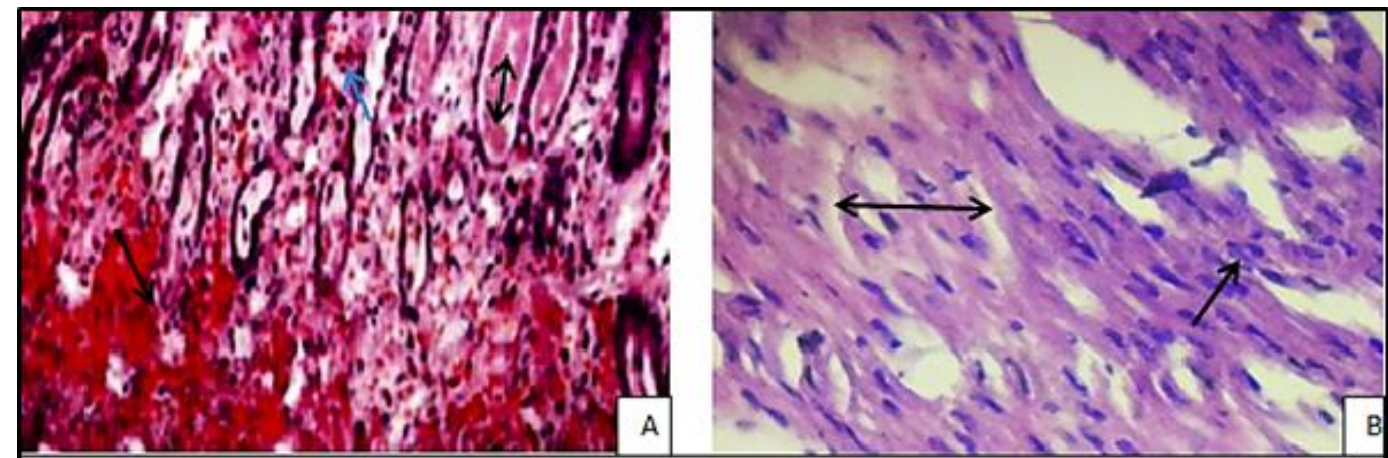

Fig.1A. Intestine of cats infected with FPV showed crypts are dilated and necrotic $\leftrightarrow$ ) and mild inflammatory cells infiltrations in the mucosal layer of intestine mainly macrophages and few neutrophils and lymphocytes $(\rightarrow)$ also there is sever hemorrhagic areas in the mucosal layer of intestine $(\longrightarrow)(\mathrm{H}$ and E stain X200). B. Heart: Heart: there is acute cellular swelling characterized by perinuclear, vacuolated edema between muscles fibers $\leftrightarrow$ ) and increased acidophilia between muscles fibers $(\rightarrow)(\mathrm{H}$ and E stain X400) 

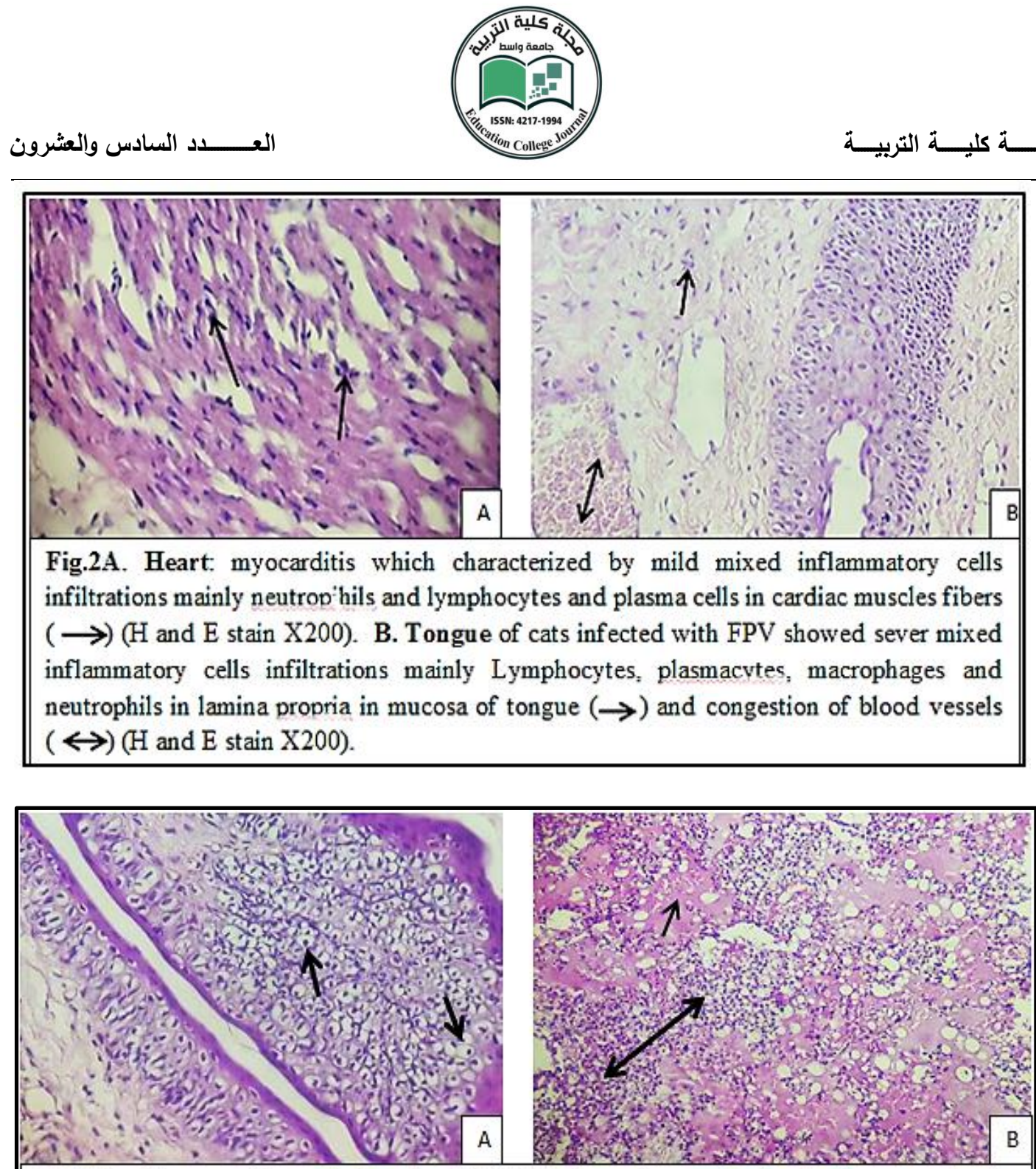

Fig.3.A. Tongue of cats infected with FPV showed sever hydropic degeneration in epithelium of mucosal tongue $(\longrightarrow)(\mathrm{H}$ and $\mathrm{E}$ stain X200). B. Lung: there is interstitial pneumonia and there is thickening of alveolar wall due to sever infiltrations of MNCs mainly lymphocytes and macrophages $(\leftrightarrow$ ) with sever areas of pulmonary edema $(\rightarrow)$ ( $\mathrm{H}$ and $\mathrm{E}$ stain $\mathrm{X} 200$ ) 


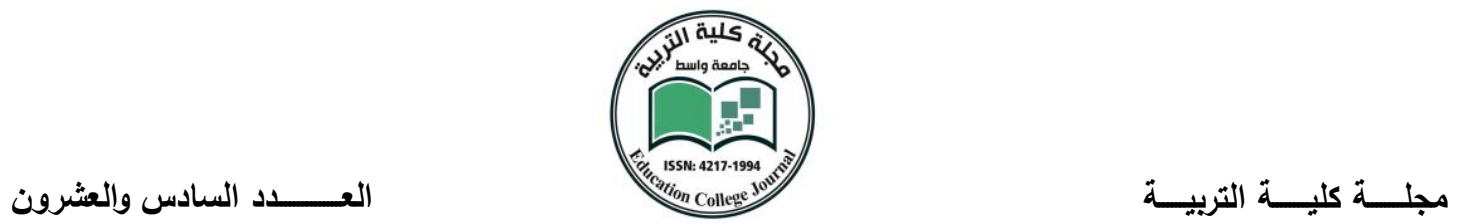

\begin{tabular}{|c|c|}
\hline 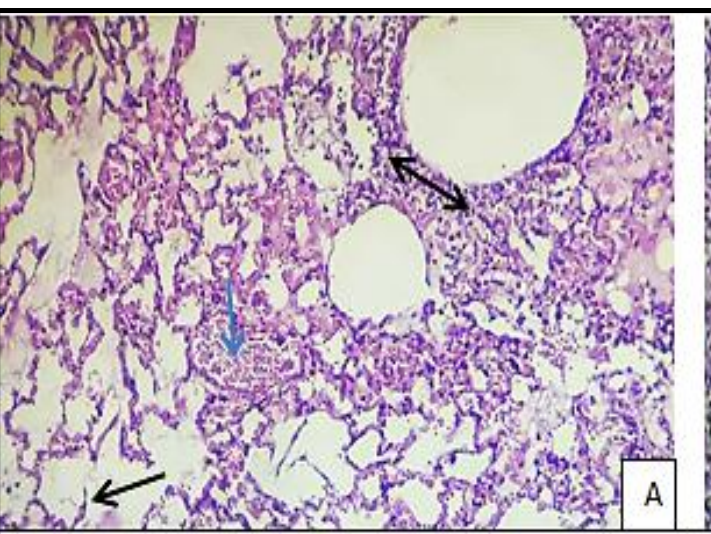 & 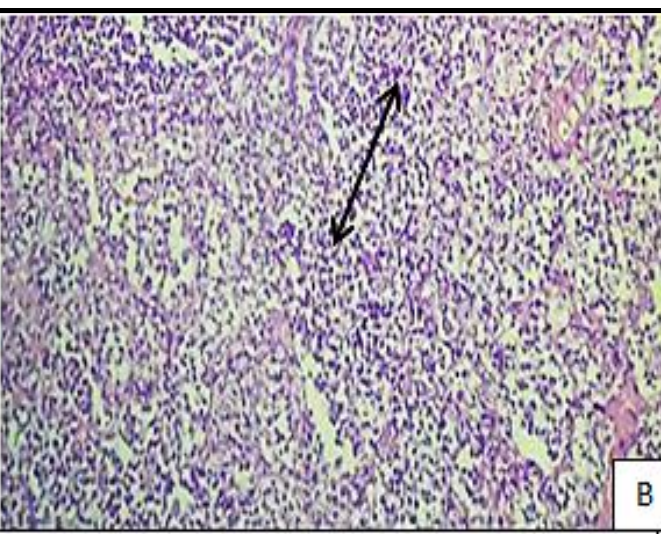 \\
\hline $\begin{array}{l}(\rightarrow)(\mathrm{H} \text { and } \mathrm{E} \text { stain } \mathrm{X} 200) \text {.B. Lung: there is } \\
\text { by sever MNCS infiltrations mainly lymphocy } \\
\text { stain } \mathrm{X} 200)\end{array}$ & $\begin{array}{l}\text { with interstitial lymphocytic infiltration } \\
\text { reas }(\rightarrow \text { with congestion of blood vessels } \\
\text { sever interstitial pneumonia characterized } \\
\text { ytes and macrophages }(\longleftrightarrow) \text { (H and E }\end{array}$ \\
\hline
\end{tabular}

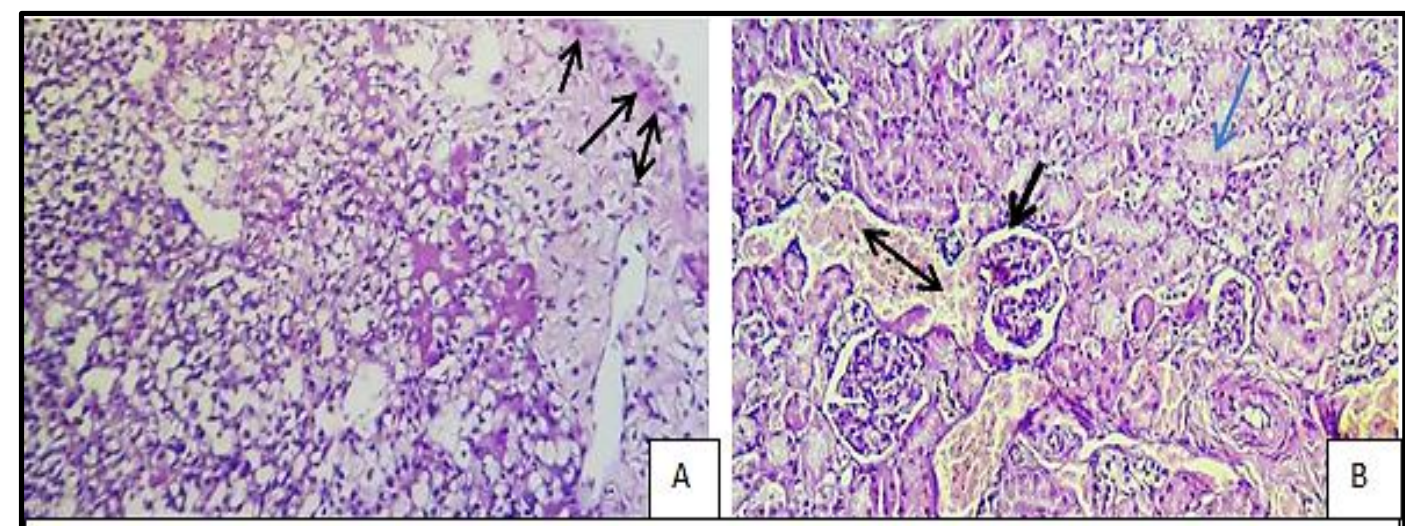

Fig.5A Pleura: there is sever inflammatory cells exudations such as lymphocytes and plasma cells and neutrophils $(\rightarrow)$ with fibrin exudates in pleural tissue $(\leftrightarrow)(\mathrm{H}$ and $\mathrm{E}$ stain X200). B. Kidney: there are tubular necrosis of proximal and distal convoluted tubules $(\rightarrow$ ) and dilation of bowman's space $(\rightarrow)$ and congestion of blood vessels $\leftrightarrow)(\mathrm{H}$ and $\mathrm{E}$ stain $\mathrm{X} 200)$. 

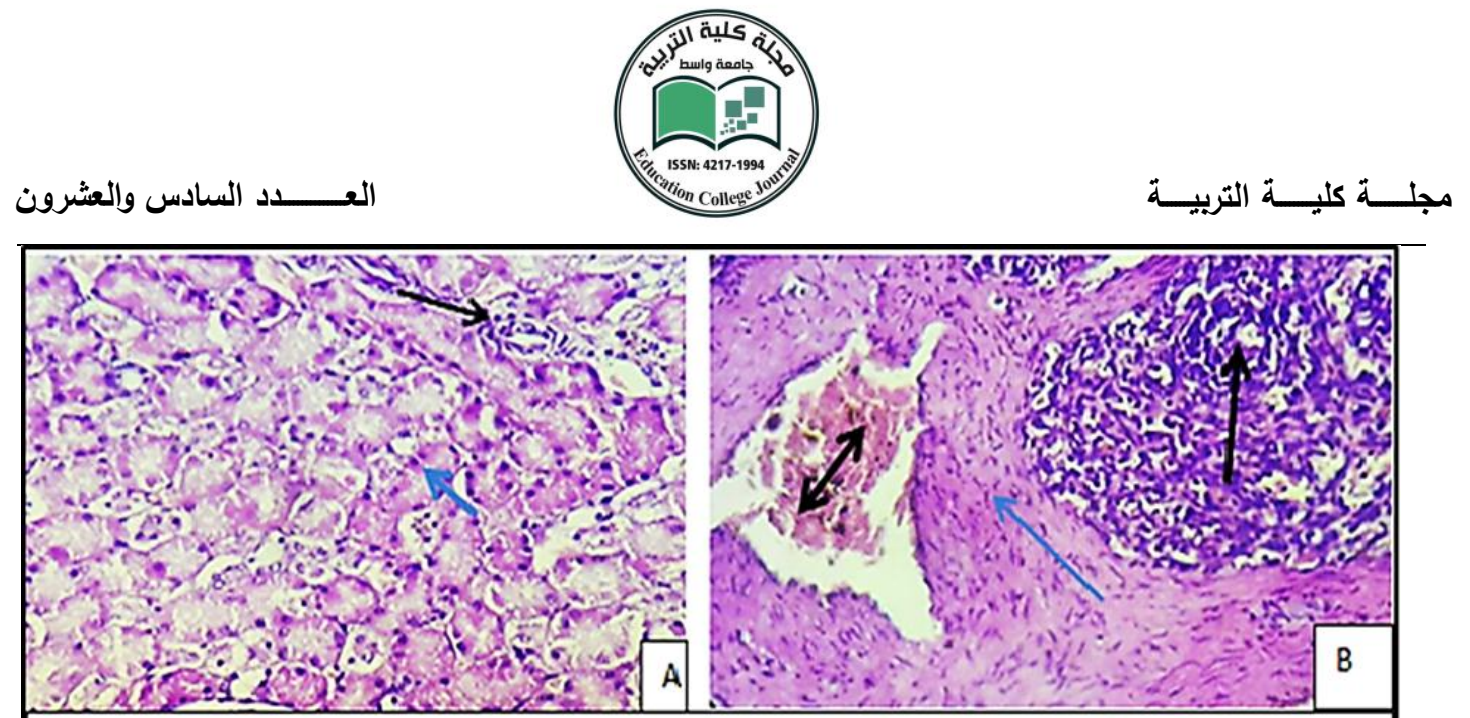

Fig.6A Kidney: there are tubular necrosis with MNCs infiltrations mainly lymphocytes $(\rightarrow)$ and presence of eosinophilic intra nuclear inclusion bodies in renal epithelium $(\rightarrow)(\mathrm{H}$ and $\mathrm{E}$ stain X400).B.Spleen: Hyperplasia of white pulp due to proliferation of the lymphocytes and macrophages in the periarterial sheath region $\leftrightarrow$ )and extensive hyperplasia of smooth muscles of trabecule $(\rightarrow)$ with congestion of blood vessels $(\rightarrow)(\mathrm{H}$ and E stain X400)

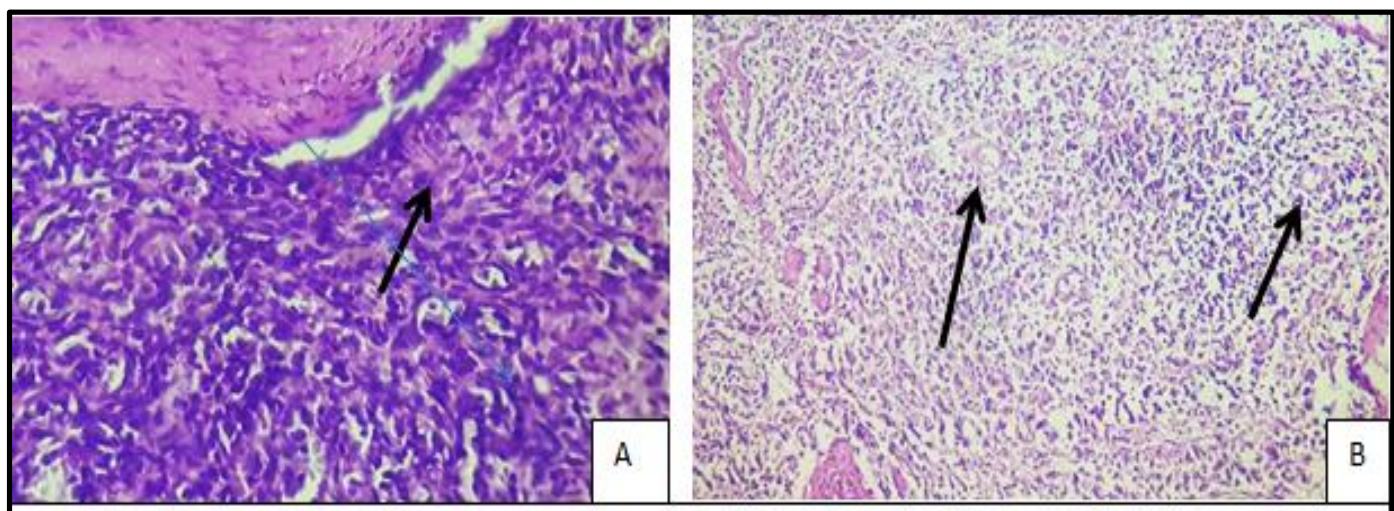

Fig.7A. Spleen: hyperplasia of white pulp with extensive proliferation of lymphocytes and macrophages $(\rightarrow$ (H and E stain X400). Fig.7B.Spleen: lymphoid depletion of white pulp due to lack of lymphocytes and macrophages around central artery in white pulp of spleen $(\rightarrow)$ (H and E stain X400). 


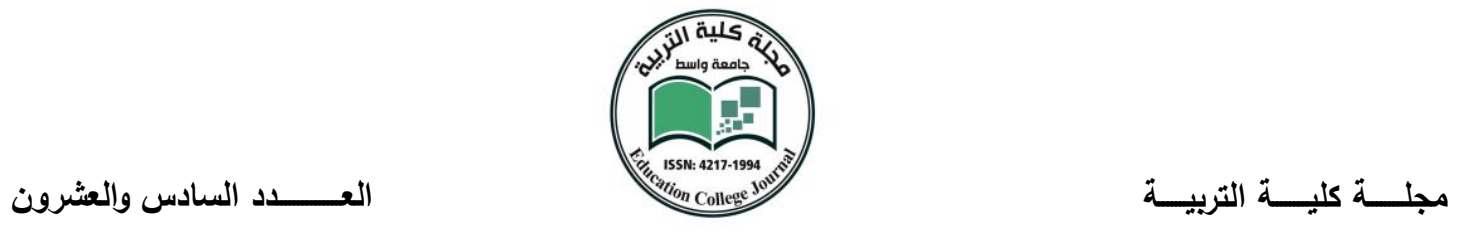

Discussion

FPV and CPV2 had a tendency to invade and replicate in the cells with characteristics of rapidly dividing, which reproduce at $\mathrm{S}$ phase of cell cycle due to expression of host DNA polymerase and this enzyme considered to be essential for virus replication, also was abundant at this stage (small ages) $(10,11)$. These viruses were known to be infected cats over the world (1). The histological susceptibility to infection begin from the tongue lining cells and act as the site of infection and multiplication of the virus and extending to all parts gastrointestinal tract principally intestine $\quad(12,13)$.

The current observations of gross and microscopic lesions were supported by (14) who showed that the virus cause extensive necrosis of epithelium crypts then cause villi shortening. Also coordinated with the outcomes of $(1,15)$ Who showed that gut suffering from hemorrhagic patches such echymotic and petechial hemorrhages as well as hardening of intestinal loop. The virus was cause severe defects occurs at many vital organs and tissues as intestine, heart, kidney, LN, spleen, lung, liver, thus cause generalized or systemic infection (16) . The present results showed huge pathological disorders in heart and kidneys as mentioned above, these outcomes were coordinated with the results ( 6,17,18), who showed that the virus can cause cardiomyopathy in kittens more than young cats due to presence of rapidly dividing cells make it highly susceptible to infection, also showed the fragmentation of muscle fibers with inflammatory signs in dogs with CPV2 . In case of the kidneys findings which supported with the observations of $(6,19,20)$ who showed the virus could isolated from kidneys of infecting animals , also showed that the generalized infection of CPV2 leads to necrosis of developing renal tubular cells may be due to viremia. The lymphatic tissues also affected from generalized infection specially spleen and other L.N , thus caused of lymphoid depletion and then cause immunosuppression, these results supported with $(1,12)$.

In case of hyperplastic changes of spleen may be occur due to severe viral infection in addition to heavily concurrent bacterial infection as shown by( 21) who recorded that the leukocytosis occur due to response to complicating secondary bacterial infection. Many authors were recorded of severe pulmonary signs that associated with FPV or CPV2 such as lung hemorrhages or edema or aleviolitis ( $22,23)$. These manifestations may be attributed to the affinity of the virus to 
replicate and invades the rapidly generating (dividing) cells of the small intestine and lymphatic tissues and also nervous tissue $(1,7,10)$. In the small ages, these type of cells which also present in heart and tongue, thus leads to infection and cause of degenerative worse effect $(4,13,18)$.

\section{Conclusion}

The current study were showed briefly, the FPV had a severe pathological effect on the studied vital organs such as intestine, heart and kidney. Further more, that the animal was threatened at any age to be infected, unless vaccinated at early ages

\section{References}

1. Greene, C.E. Infectious diseases of the dog and cat. (4th ed.). Saunders, 2012. An imprint of Elsevier Inc, Missouri, USA.

2. Battilani, M., Bassani, M., Forti, D., Morganti, L.,. Analysis of the evolution of feline parvovirus (FPV). Veterinary Research Communications . 2006. 30, 223-226.

3. Van Vuuren M, Steinel A, Goosen J, Lane E, Van der Lugt J, Pearson J, Truyen U. Feline panleukopenia virus revisited: molecular characteristics and pathological lesions associated with three recent isolates. J Sou Afri Vet Associ. 2000 .71(3): 140-143 (En.).

4. Greene CE, Addie DD . Feline parvovirus infections . In : Greene CE (ed). Infectious disease of dog and cats . Louis :Saunders .Elsevier ; 2006: 78-88.

5. Addie, D., Toth, S., Thompson, H., Greenwood, N. and Jarret, O. Detection of feline parvovirus in dying pedigree kittens. Vet Rec. 1998. 142:353-356.

6. Al-Bayati HAM. Detection and isolation of canine parvovirus in Iraq. MSc thesis. 2009. College Vet Med, University of Baghdad.

7. Poncelet L, Héraud C, Springinsfeld M, Ando K, et al . Identification of feline panleukopenia virus proteins expressed in Purkinje cell nuclei of cats with cerebellar hypoplasia. Vet J. 2013. $196:$ 381-387.

8. Al-Bayati HAM. Detection of feline Parvovirus (FPV) from Cats infected with Enteritis Using rapid test and Polymerase Chain Reaction in Iraq. 2016 . Data not published .

9. Luna, H.T. and Lee, G. "Manual of Histopathological Staining Method of Armed Forces Institute of Pathology".1968. $3^{\text {rd }}$ Ed .McGraw-Hill Book Co. New York. USA.

10. Steinel, A., Munson, L., Van Vuuren, M. and Truyen, U. Genetic characterization of feline parvovirus sequences from various carnivores. J. Gen. Virol. 2000 . 81 : 345-350.

11. Decao N, Desario C, Campolo M, Elia G, Martella V, Ricci D, Lorusso E, Buonavoglia C. Clinical and Virological findings in pups naturally infected by canine parvovirus type 2 Glu-426 mutant. J Vet Diagn Invest. 2005 . 17: 133-138.

12. Truyen, U. (2006). Evolution of canine parvovirus: a need for new vaccines? Vet. Microbiol., 117(1): 9-13. 
13 . McKnight CA, Maes RK, Wise AG, Kiupel M. Evaluation of tongue as a complementary sample for the diagnosis of parvoviral infection in dogs and cats. J Vet Diagn Invest. 2007. 19: 409-413.

14. Pirarat, N , Kaewamatawong $\mathrm{T}$, Techangamsuwan, S. A RETROSPECTIVE IMMUNOHISTOCHEMISTRY STUDY ON FELINE PANLEUKOPENIA VIRUS, INDUCED ENTERITIS, IN CATS. Thai J. Vet. Med. 2002. Vol. 32 No. 4, 31.

15. Mosallanejad, B., Avizeh, R and N. M. Ghorbanpoor. Antigenic detection of Feline Panleukopenia virus (FPV) in diarrhoeic companion cats in Ahvaz area. Iran J Vet Res, Shiraz University. 2009. Vol. 10, No. 3, Ser. No. 28, pp 289-293.

16. Nho WG, Sur JH, Doster AR, Kim SB. Detection of canine parvovirus in naturally infected dogs with enteritis and myocarditis by in situ hybridization. J Vet Diagn Invest.1997 . 9: 255-260.

17. Otto CM, Drobatz KJ, Soter C. Endotoxemia and tumor necrosis factor activity in dogs with naturally occurring parvoviral enteritis. J Vet Intern Med 1997;11(2): 65-70.

18. Meurs, M. Fox, R, Alexander L, Magnon, S, et al. Molecular Screening by Polymerase Chain Reaction Detects Panleukopenia Virus DNA in Formalin-Fixed Hearts from Cats with Idiopathic Cardiomyopathy and Myocarditis. Cardiovasc Pathol 2000. Vol. 9 , No. $2: 119-126$

19. Weissenbock, H. and Burtscher, H. Fluorescence serological and histological studies of antigen distribution in parvovirus infections in dogs and cats. Zentralbl. Veterinarmed. 1991. 38(7): 481-491.

20. Langhaus, C. and Studdert, M.J. Generalized parvovirus disease in neonatal pups. J. Am. Vet. Med. Assoc. 1982. 181: 41-45.

21. Boosinger, T.R.; Rebar, A.H. and DeNicola, D.B. Bone marrow alterations associated with canine parvo viral enteritis. Vet. Pathol. 1982. 19: 558-561.

22. Robinson WF, Huxtable CR, Pass DA. Canine parvoviral myocarditis: a morphological description of the natural disease. Vet Pathol . 1980 .17(3):282-93.

23. Turk J, Miller M, Brown T, et al. Coliform septicemia and pulmonary disease associated with canine parvoviral enteritis: 88 cases (1987-1988). J Am Vet Med Assoc. 1990. 196(5):771-3. 